\title{
O OLHAR SOCIOLÓGICO DE OTÁVIO DULCI SOBRE A “QUESTÃO REGIONAL"1
}

\author{
Antônio Dimas Cardoso ${ }^{2}$ \\ Lucas Tibo Saraiva ${ }^{3}$
}

\begin{abstract}
RESUMO: O objetivo deste artigo é o de refletir sobre a contribuição do sociólogo e cientista político Otávio Soares Dulci (1948-2018) na análise da “questão regional” e suas interfaces com o projeto de desenvolvimento das elites periféricas, no contexto político pós-revolução de 1930. Argumentamos que Dulci problematiza a interpretação sociológica da modernização no Brasil, tendo o estado de Minas Gerais como principal referência de investigação. Com essa discussão, o que se almeja é reconhecer o legado de Otávio Dulci para o Pensamento Social Brasileiro, não somente como analista dos cânones das Ciências Sociais produzidas no país, mas também como formulador da sociologia histórica e do desenvolvimento, que incorpora na dimensão macrossocial o conjunto de valores e ação política de grupos empresariais.
\end{abstract}

PALAVRAS-CHAVE: Projetos de desenvolvimento. Elites políticas. Questão regional. Otávio Dulci.

\footnotetext{
${ }^{1}$ Trabalho originalmente apresentado no GT Pensamento Social no Brasil, do $19^{\circ}$ Congresso Brasileiro de Sociologia, UFSC, Florianópolis-SC, Brasil, 09 a 12 julho de 2019, com reformulações para esta edição.

${ }^{2}$ Doutor em Sociologia pela Universidade de Brasília. Professor permanente do Programa de Pós-Graduação em Desenvolvimento Social e do Departamento de Política e Ciências Sociais, da Universidade Estadual de Montes Claros. E-mail: antonio.dimas@unimontes.br. Orcid: https://orcid.org/0000-0001-5904-716X.

${ }^{3}$ Mestre pelo Programa de Pós-Graduação em Desenvolvimento Social da Universidade Estadual de Montes Claros. E-mail: lucas.tibo10@gmail.com. Orcid: https://orcid.org/00000002-2270-7934.
} 


\title{
OTÁVIO DULCI'S SOCIOLOGICAL LOOK AT THE "REGIONAL ISSUE"
}

\begin{abstract}
The objective of this article is to reflect on the contribution of sociologist and political scientist Otávio Soares Dulci (1948-2018) in the analysis of the "regional issue" and its interfaces with the project of development of peripheral elites, in the postrevolution political context of 1930. Dulci problematizes the sociological interpretation of modernization in Brazil, with the state of Minas Gerais as the main research reference. With this discussion, the aim is to recognize the legacy of Otávio Dulci for Brazilian Social Thought, not only as an analyst of the canons of social sciences in Brazil, but also as a formulator of historical sociology and development, which incorporates in the macrosocial dimension the set of values and political action of business groups.
\end{abstract}

KEYWORDS: Development projects. Political elites. Regional issue. Otávio Dulci.

\section{OPINIÓN SOCIOLÓGICA DE OTÁVIO DULCI SOBRE LA "CUESTIÓN REGIONAL"}

RESUMEN: El propósito de este artículo es reflexionar sobre la contribución del sociólogo y politólogo Otávio Soares Dulci (1948-2018) en el análisis de la "cuestión regional" y sus interfaces con el proyecto de desarrollo de las élites periféricas, especialmente las ubicadas en Minas Gerais, en el contexto político posterior a la Revolución de 1930. Dulci problematiza la interpretación sociológica de la modernización en Brasil, con el província de Minas Gerais como principal referencia de investigación. Con este debate, pretendemos reconecer el legado de Otávio Dulci para el Pensamento Social brasileño, no solo como analista de los cánones de las Ciências Sociales, en Brasil, sino también como formulador de la sociologia histórica y del desarrolho, que incorpora en la dimensión macrossocial el conjunto de valores y la acción política de los grupos empresariales.

PALABRAS CLAVE: Proyectos de desarrollo. Elites políticas. Cuestión regional. Otávio Dulci. 


\section{INTRODUÇÃO}

Conhecido e admirado nos meios acadêmicos por sua discrição pessoal, generosa sabedoria e peculiar capacidade analítica, Otávio Soares Dulci (1948-2018), ao longo de sua carreira universitária, ofereceu ao Pensamento Social produzido no Brasil um estilo de interpretação que possibilita a revitalização da sociologia histórica sobre o processo de desenvolvimento, com centralidade na chamada "questão regional". Pesquisador atento às complexidades de experiências nacionais de modernização, com sua transposição para o plano das relações interregionais, Dulci foca no modelo que chamou de "intermediário" para estudar o processo regional de industrialização que começou a ser incrementado no país a partir da Revolução de 1930, tendo Minas Gerais como principal campo empírico de análise.

No seu estudo sobre a evolução corporativa da burguesia, seguindo a trilha sociológica aberta por Florestan Fernandes, Dulci sugere que o primeiro passo a ser considerado, ao lado dos eixos transnacionais de convergência, é observar a relevância dos recortes subnacionais. Regiões, províncias, comunidades autônomas (como também, em nível micro, as instâncias locais, municipais) se tornam objetos legitimos de investigação por seu próprio mérito, não apenas como resíduos de uma etapa a ser ultrapassada no trajeto para um mundo globalizado (DULCI, 1999, p. 17). Por se tratar de uma abordagem crucial no Pensamento Social Brasileiro, desde a Primeira República, Dulci procura enfatizar o legado do "estudo sistemático"4 de Oliveira Vianna, sobre as populações meridionais do Brasil (Vianna, 1938), no que pese sua preferência pelo estudo pioneiro de um intelectual de sociologia histórica que ele considerava ter sido mantido em "relativa obscuridade": Manoel Bomfim, autor do livro clássico América Latina: males de origem, publicado pela primeira vez em 1903. Para Dulci (2000, p. 234), "o modelo ibérico de colonização, alvo da

\footnotetext{
${ }^{4}$ Esta expressão foi utilizada pelo próprio Dulci, ao ser referir às publicações de Oliveira Vianna, em plano de trabalho de Sociologia Brasileira enviado por ele a um dos autores deste artigo, em 2006, durante curso no Programa de Pós-Graduação em Desenvolvimento Social da Universidade Estadual de Montes Claros (Minas Gerais, Brasil).
} 
crítica de Bomfim, seria mais tarde revalorizado por Gilberto Freyre como elemento fundamental de sua investigação do sistema de relações raciais que se constituiu no Brasil".

De Gilberto Freyre, Dulci (2000, p. 234) recupera a perspectiva sócio-histórica e o seu projeto político e cultural ancorado no "regionalismo", de modo a contribuir "para desmontar a crença nas ideias deterministas que persistiam como explicações do atraso do Brasil". Esse giro teórico promovido inicialmente por Bomfim e na sequência por Freyre, na visão de Dulci (2000, p. 234), representou "uma notável contribuição da ciência social brasileira ao avanço do conhecimento global nesse domínio do saber". É desse arcabouço teórico que Dulci procura dar centralidade à questão regional, em seus estudos comparados, na relevância dos recortes subnacionais. Dulci segue a tradição de estudos clássicos que procuram estabelecer relações entre região e nação, no sentido examinado por pesquisadores contemporâneos como Mariana Chaguri (2011, p. 12), com foco no argumento de que "a coesão nacional seria decorrente da combinação entre a diversidade regional, percebida e construída culturalmente".

Ao detectar estruturas regionais de poder, o sociólogo mineiro procura possíveis influências de fatores políticos sobre a lógica da distribuição espacial do capital, que condicionam o desenvolvimento de grupos sociais e a configuração do Estado. Para ele, o desequilíbrio entre regiões ganha relevância como questão social a partir do momento em que a economia nacional transita para a fase industrial. No entanto, o olhar sociológico de Dulci evita a utilização do consagrado modelo "centro-periferia", que aparece primeiramente em Werner Sombart, no seu O capitalismo moderno, de 1902, pois tal modelo sugere uma percepção demasiado homogênea da "periferia", ou seja, de todo espaço que não constitui o "centro".

Como se sabe, o modelo dicotômico centro-periferia foi retomado pelo economista argentino Raúl Prebisch, na década de 1940, em seus estudos sobre o desenvolvimento periférico na América Latina (cf. PREBISCH, 1949). Dulci reconhece a importância da abordagem estrutural, que oferece a possibilidade da generalização, mas argumenta que "perde-se em precisão" (DULCI, 1999, p. 18). Ao mesmo tempo, 
também evita abordar a mudança social somente como processo interno, autocontido. Dulci prefere não negligenciar o impacto da emulação internacional, da difusão de ideias, da influência externa, como foi o caso da reprodução do liberalismo no Brasil, pelas elites inter-regionais. Para o autor, "a construção da sociologia em termos globais derivou de esforços de indivíduos e de grupos que costumam ser identificados por sua raiz nacional e, mais ainda, pelo envolvimento com questões de seu tempo" (DULCI, 2000, p. 225).

A tese de Dulci reside na afirmação de que o elemento central do modelo de modernização conservadora, experimentado pelo Brasil, é a relevância de ações políticas sobre fatores de mercado. Problematiza que, historicamente, predominou no país uma coalizão de elites, unindo setores tradicionais e emergentes, onde se teria diversas lógicas intermediárias que combinam situações e fases distintas. Para a explicação dessas fases, Dulci indica duas referências fundamentais: Guerreiro Ramos (1996) e Florestan Fernandes (1962), dois autores de grande envergadura no panorama do Pensamento Social no Brasil, e que mantinham posições divergentes acerca do problema que Dulci se ocupou durante sua trajetória acadêmica como docente de sociologia e ciência política.

Mineiro da Zona da Mata, Dulci trabalhou com José Murilo de Carvalho durante seu doutoramento no Instituto Universitário de Pesquisas do Rio de Janeiro, já como docente e pesquisador da Universidade Federal de Minas Gerais. Buscou no estudo da industrialização mineira dos anos 1940 e 1950, antecedentes empresariais para compreensão das relações de poder na atualidade, com foco no problema das desigualdades sociais. Por fim, encerrou sua carreira acadêmica na Pontifícia Universidade Católica de Minas, em Belo Horizonte, no Curso de Relações Internacionais. Em seus estudos, Dulci contribuiu para vitalizar por onde passou a chamada "sociologia histórica", apoiando-se nos fundamentos comparativos para

\footnotetext{
${ }^{5}$ Otávio Soares Dulci entende a sociologia histórica como sendo um "alicerce teórico" que possibilita explorar antecedentes, materiais históricos, origens, trajetórias, eventos, processos temporais para compreensão de problemas sociais contemporâneos, cujo ponto de partida é a reflexão sobre a heterogeneidade da modernização e diversidade regional no Brasil, tanto no aspecto econômico quanto nos aspectos político, social e cultural, identificando-se a relação
} 
compreender a capacidade política das elites periféricas que se uniram em torno da implementação do projeto de desenvolvimento.

Para Dulci (1999), a trajetória do Brasil tem sido marcada pela dialética entre a primazia do conjunto e a afirmação de suas partes: o de integração e o de particularização, de nação e região. $O$ seu esforço epistemológico, para compreender o Brasil, foi o de procurar ressaltar o nexo entre variações econômicas e políticas no processo de modernização, incorporando o problema das identidades regionais como recurso político, no esforço de interpretação do conjunto e de sua dinâmica. Entende que, desde a Revolução de 1930, foi estabelecido no país um formato organizativo que vigora até a atualidade.

Tendo em vista as questões apontadas aqui, este trabalho tem como objetivo discutir a interpretação sociológica de Otávio Dulci do desenvolvimento e da modernização no Brasil, centrado principalmente em sua análise sobre a "questão regional”, tendo o estado de Minas Gerais como referência de investigação. Procuramos evidenciar a singularidade do sociólogo e cientista político mineiro na análise sobre a capacidade política das elites, na formulação e implementação do projeto de desenvolvimento regional, experimentado historicamente. Com esta discussão, o que se almeja é reconhecer o legado de Otávio Dulci para o Pensamento Social no Brasil, não somente como analista dos clássicos brasileiros, mas também como formulador de uma perspectiva interpretativa da sociologia histórica e do desenvolvimento.

\section{APLICABILIDADE DA SOCIOLOGIA PARA A INTERPRETAÇÃO DO BRASIL}

Assim como outros cientistas sociais, Otávio Dulci se preocupa em considerar a sociologia brasileira a partir de um dilema fundante: o da generalidade do Pensamento Social, de um lado, e da sua particularidade, de outro. Tal dilema se traduz numa questão de método. Nos termos do autor,

entre essas esferas.

Temáticas, Campinas, 29, (57): 64-87, fev./jun. 2021 
o modelo nomotético de ciência orienta a investigação para o estabelecimento de proposições gerais sobre fenômenos, com vistas a alcançar eventualmente um conjunto sistemático de leis. O modelo idiográfico, por sua vez, tem como alvo a descrição ou interpretação de fenômenos singulares no espaço e no tempo; seus praticantes se concentram na realidade empírica, descartando a meta de construção teórica cumulativa (DULCI, 2000, p. 224).

Para ilustrar esta questão, Dulci recupera as polêmicas ocorridas na década de 1950 entre dois eminentes sociólogos brasileiros: Guerreiro Ramos e Florestan Fernandes. Esse período se constituiu extremamente fecundo, de problematização acerca do papel das Ciências Sociais para o desenvolvimento nacional e de criação de estilos distintos de fazer Ciências Sociais, ou, em outras palavras, de construção de padrões intelectuais peculiares. Esses dois sociólogos representaram, se não duas correntes sociológicas nacionais, dois modos distintos de pensar e fazer pesquisa nas Ciências Sociais brasileiras.

Para Dulci, Guerreiro Ramos se notabilizou pelo esforço de fundamentar o projeto de uma sociologia nacional, assumindo posição mais próxima da visão idiográfica, já que ele sustentava a necessidade de uma sociologia ancorada aos interesses nacionais, apesar de não prescindir de um esforço qualitativo de conjunto; ao passo que Florestan Fernandes, ainda de acordo com Dulci, tendia a pensar a relação entre a atividade científica e o seu contexto menos como um dado e mais como um problema a ser equacionado. Para nosso autor, ambas as posições são relevantes para a prática científica. Em suas palavras:

A primeira tem a ver com os condicionamentos econômicos e socioculturais a que se sujeita o desenvolvimento institucional da ciência. A segunda, com a influência de outros sistemas de normas e valores sobre as escolhas dos cientistas, escolhas pretensamente neutras, mas que ocultam inspirações filosóficas, políticas e ideológicas (DULCI, 2000, p. 229). 
A busca por uma autonomia nacional e por uma descolonização da mentalidade predominante passava, na leitura de Dulci, por uma crítica contundente ao Pensamento Social produzido no país e pela consequente elaboração de uma sociologia autêntica que comportasse um filtro às ideias estrangeiras, bem como uma expressa vinculação aos problemas da nação brasileira. Por esse motivo, Guerreiro Ramos acusa, segundo Dulci (2000, p. 228), boa parte dos pensadores brasileiros de fazer uma "sociologia enlatada", isto é, que simplesmente era reproduzida no Brasil e consumida como uma "conserva cultural".

É preciso salientar, seguindo o argumento de Dulci, que tanto Guerreiro Ramos como Florestan Fernandes afirmavam o caráter universal que as Ciências Sociais possuíam enquanto constituinte do mundo da ciência. A divergência é a de que, para o primeiro, as especificidades nacionais teriam que direcionar os rumos do conhecimento sociológico, de modo que este estivesse a serviço do progresso social e não se emaranhasse em um "saber alienado" (DULCI, 2000, p. 229). Nesse sentido, seria premente o estabelecimento de uma agenda de pesquisas macrossociológicas que pudesse subsidiar os governos na consecução de projetos de desenvolvimento nacional.

De modo distinto do de Guerreio Ramos, Dulci observa que Florestan Fernandes concebe relativa autonomia ao mundo científico, o que acarreta na valorização de "estudos de comunidade", pois, na ótica do sociólogo paulista, ao se perseguir o desenvolvimento da sociologia enquanto ciência, contribui-se para o conhecimento mais aprofundado sobre os problemas sociais brasileiros (DULCI, 2000, p. 230). Fato é que, para Florestan Fernandes, a busca por soluções para os problemas nacionais não deve atropelar os cânones científicos, pois, se assim fosse, a sociologia estaria condenada a intervenções pragmáticas de forma irrefletida. Por esse motivo, para este autor, a pesquisa sociológica deveria ter uma relativa autonomia. $\mathrm{Na}$ visão de Dulci, Florestan Fernandes imagina que "a articulação do cientista com o meio se exprime no antes e no depois. O durante, a pesquisa, deve estar livre de injunções externas" (DULCI, 2000, p. 229, grifo do autor). 
As distintas concepções do papel da ciência na sociedade que os sociólogos possuem permite identificar critérios também distintos na análise do curso do Pensamento Social no Brasil. Assim, pode-se dizer que os processos de "secularização" e "racionalização" são norteadores para Florestan Fernandes pensar o florescimento e consolidação das Ciências Sociais no Brasil, pois, segundo Dulci (2000, p. 230), o sociólogo paulista "interessa-se, sobretudo, pela constituição de padrões de trabalho científico ao longo do tempo, relacionando-a com fatores estruturais, políticos e culturais". Assim, para Florestan Fernandes, a sociologia surge realmente quando rompe com o ensaísmo e absorve a racionalidade típica do trabalho científico. Diferente é o caso de Guerreiro Ramos, que concebe uma sociologia brasileira a partir do critério da vinculação das ideias aos problemas da realidade nacional, seguindo um viés marcadamente pragmático.

Ao buscar referências em Guerreiro Ramos e Florestan Fernandes, Dulci (2000, p. 231) defende a posição teórica de que "a sociologia construiu no Brasil uma tradição própria, ao buscar respostas para as questões que se apresentavam a partir da realidade social do país". Argumenta ainda que a sociologia procura estabelecer proposições gerais sobre fenômenos sociais. No entanto, desde o início, a partir de diferentes tradições nacionais, a sociologia brasileira se dirige a problemas específicos. Assim, o resultado dessas orientações passa a ser uma sociologia que, ao investigar a realidade próxima, o faz sobre um alicerce teórico que lhe possibilita alcançar relevância científica mais ampla, no sentido nomotético, com predileção pela investigação do que o Brasil oferece de singular.

O sociólogo mineiro observa que em meados da década de 1950 “[...] surgiram as primeiras reflexões sistemáticas sobre a evolução do pensamento social brasileiro, acompanhadas de tentativas de classificação de suas fases e de suas principais perspectivas de análise" (DULCI, 2000, p. 227). Como vimos, tanto Florestan Fernandes quanto Guerreiro Ramos se destacaram pelo esforço de sistematização sobre a evolução das Ciências Sociais no Brasil. Contudo, para Dulci, é preciso incorporar também intelectuais como Manoel Bomfim, Oliveira Vianna, Gilberto Freyre, Darcy Ribeiro, Sérgio Buarque, Raymundo Faoro, Celso Furtado, Hélio 
Jaguaribe, Luciano Martins, Francisco de Oliveira, Antonio Candido, Costa Pinto, dentre outros, que também ofereceram contribuições preciosas no sentido de esclarecer as origens e momentos-chave do Pensamento Social produzido no Brasil. Em que pese a relevância teórica desses autores mencionados, pode-se dizer que, para Dulci, as interpretações de Florestan Fernandes e de Guerreiro Ramos se tornaram paradigmáticas.

A análise das divergências teóricas e metodológicas entre os sociólogos permite a Dulci concluir como a sociologia brasileira conseguiu imprimir um teor generalizante a partir do estudo das peculiaridades de seus problemas sociais. Segundo o sociólogo e cientista político, “embora seus autores quase sempre tratassem do Brasil em si, abriram, explícita ou implicitamente, perspectivas de análise comparativa que permitiam situar o caso brasileiro em face de casos equivalentes ou contrastantes" (DULCI, 2000, p. 231).

Ao analisar historicamente modelos políticos de desenvolvimento regional, Dulci se aproxima mais da vertente sociológica institucionalizada por Florestan Fernandes, no âmbito dos projetos realizados inicialmente no Centro de Sociologia Industrial e do Trabalho (CESIT), como A empresa industrial em São Paulo e Economia e sociedade no Brasil: análise do subdesenvolvimento (1962). Dulci reconhece que os estudos sobre as elites empresariais paulistas, realizados por Florestan Fernandes e por Fernando Henrique Cardoso com sua tese de livre docência Empresário industrial e desenvolvimento econômico no Brasil, defendida em 1963, tornaram-se referências fundamentais de sociologia do desenvolvimento no Brasil - ou do subdesenvolvimento, como é a tese defendida por Florestan Fernandes - sobre a questão empresarial-industrial e as articulações das elites e suas corporações. Esses projetos estimularam posteriormente pesquisas em outras universidades brasileiras, além do que ocorreu no âmbito da Comissão Econômica para América Latina e o Caribe (CEPAL) no final da década de 1960, com a publicação de Dependência e desenvolvimento na América Latina: ensaios de interpretação sociológica, de Fernando Henrique Cardoso e Enzo Faletto (1984). Para Helayel (2020, p. 2.), este trabalho representa o "ponto de chegada da sociologia histórica de Cardoso", cuja trajetória de suas análises, numa perspectiva histórico-comparada, culmina 
com esta fase de produção intelectual no âmbito da CEPAL, durante a estadia no Chile.

Ao buscar orientações para suas interpretações, Dulci (1999, p. 150) distingue duas posições polares sobre o desenvolvimento desigual, de tipos político-institucionais que se tornaram hegemônicos na região. A primeira posição, que ele considerava mais clássica, atribui protagonismo ao empresariado no processo de modernização do país, com um cenário que contrapõe o afã desenvolvimentista, sob auspícios da burguesia nacional. Sobre esse ponto, Dulci afirma que esta posição está fundamentada em duas antinomias que se interpõem: segmentos modernizantes versus segmentos tradicionais; nação versus imperialismo. É nesse campo que Dulci situa as contribuições fundamentais da CEPAL, bem como do Instituto Superior de Estudos Brasileiros (IBES), dos anos 1950 e da primeira metade dos anos 1960, destacando a contribuição de autores como Guerreiro Ramos, Hélio Jaguaribe, Celso Furtado e também as teses do etapismo do Partido Comunista, principalmente por meio de Nelson Werneck Sodré. No entanto, Dulci afirma que esta primeira posição cedeu lugar a uma profunda revisão a partir da ruptura de 1964, colocando em xeque a tese do papel emancipador da burguesia nacional. A segunda posição expressa esse deslocamento de perspectiva, pois a agenda de pesquisa se volta para a primazia do Estado na condução do processo de modernização, sob o protagonismo dos militares e tecnocratas, do "estamento burocrático" na formação brasileira.

Sem negligenciar as contribuições de Fernando Henrique Cardoso sobre o diagnóstico das alianças corporativas (Cardoso, 1964), Dulci se associa de forma mais contundente à crítica de Florestan Fernandes sobre a modernização protagonizada pela burguesia nacional, referenciando-se também nas análises de uma publicação posterior do catedrático paulista: A revolução burguesa no Brasil (1976). Na construção de suas análises, Dulci ainda retoma referências fundadoras sobre o empresariado e suas estruturas de poder nos estudos pioneiros do projeto "Grupos Econômicos”, de 1962 a 1967, realizados no antigo Instituto de Ciências Sociais da Universidade do Brasil, do Rio de Janeiro (VILLAS BÔAS, 2019). Desses estudos, sua principal fonte de consulta foi o trabalho Industrialização, burguesia nacional 
e desenvolvimento (1968), de Luciano Martins, uma das principais referências do projeto "Grupos Econômicos".

Com sua sociologia histórica, Dulci se propôs a encontrar determinados traços que distinguem o processo de desenvolvimento no Brasil, com especial interesse no conteúdo político da experiência de Minas Gerais. Parte da proposição de que a formação da industrialização no país enseja uma pluralidade de experiências regionais "irredutíveis à via paulista" (DULCI, 1999, p. 32). Seu foco foi o de compreender a expansão do capital e a dinâmica criada pelos setores empresariais para além do eixo paulista. Em suas pesquisas, Dulci detectou uma heterogeneidade de modelos de modernização e sua aplicabilidade entre as elites interregionais. Mais ainda, nosso autor estabelece vínculos entre regionalismo e nacionalismo, exatamente por serem ideias que se articularam no pensamento econômico e cultural das elites mineiras, conforme expressa no seguinte trecho:

$\mathrm{Na}$ questão mínero-siderúrgica, a defesa dos 'interesses de Minas' era identificada com a defesa dos interesses do país, revestindo-se de conteúdo estratégico alusivo à segurança nacional. É possível traçar um paralelo desta ideia com a visão geopolítica da elite mineira a respeito de seu papel no Brasil (DULCI, 1999, p. 207).

Em sua busca pelas finalidades pragmáticas do trabalho científico, Dulci estabelece nexos entre o avanço do conhecimento sociológico e a sua utilidade para a implementação de projetos nacionais e o desenvolvimento desigual. ${ }^{6}$ Para isso, procura identificar grupos sociais, indivíduos no curso de sua ação política ou no exercício da representação corporativa, mediante um sistema de instituições humanas, de pessoas identificadas

\footnotetext{
${ }^{6}$ Em seu livro Política e recuperação econômica em Minas Gerais (1999), Otávio Dulci utiliza duas fontes para problematizar o conceito de "desenvolvimento desigual": Thorstein Veblen, autor de A Alemanha Imperial e a Revolução Industrial (1974), e Leon Trotski, autor de História da Revolução Russa (1967). Lança mão desses dois autores clássicos para problematizar a possibilidade de "vantagem do atraso", de combinações específicas de diferentes contextos do desenvolvimento histórico.
} 
no empresariado mineiro. Almeja compreender o desenvolvimento contemporâneo a partir de bases erigidas pela industrialização das décadas de 1940 e 1950, sob a ressonância da Revolução de 1930, deslocando o debate centro-periferia para o modelo que o autor chamou de intermediário. O padrão intermediário, adotado pelo autor, implica analisar um contexto regional como sendo um eixo de convergência, da economia (no caso, pela via da industrialização) e da ideologia. Esse padrão parece se ajustar a diversas experiências de desenvolvimento do Centro-Sul, no que diz respeito aos esforços internos de mobilização política no sentido de incremento da economia regional.

Assim, Dulci constata que a história da industrialização brasileira envolve múltiplas possibilidades regionais, não se restringindo a São Paulo, notadamente em unidades-vizinhas como Rio de Janeiro e Minas Gerais. No entanto, estende também sua análise comparativa a outros três estados brasileiros, cujos processos de modernização revelam combinações diferentes de fatores políticos e econômicos: Rio Grande do Sul, Paraná e, finalmente, Bahia. Em suas palavras, esses casos "corresponderam a projetos de modernização em que assumiu crescente importância a ação do poder público (sob a forma de planejamento, suporte financeiro ou mesmo investimento direto) como contrapeso a desvantagens comparativas" (DULCI, 1999, p. 32-33).

$\mathrm{O}$ que o cientista social observa em suas pesquisas sobre o desenvolvimento e a modernização é que os projetos de desenvolvimento regional derivam fundamentalmente de razões político-estratégicas de cunho nacional, dependendo do contexto político e da integração pragmática de suas elites e seu dinamismo corporativista. Nessa perspectiva de análise, o caso de Minas Gerais se torna emblemático, como objeto legítimo de investigação por seu próprio mérito, com capacidade de fundamentar análises comparativas teoricamente orientadas. 


\section{POLÍTICAS DE DESENVOLVIMENTO E A “QUESTÃO REGIONAL"}

Das discussões entre os modelos nomotético e idiográfico que perpassam o universo das Ciências Sociais, Dulci destaca o método comparativo como ponto interessante de equacionamento, visto que parte de determinadas generalizações, mas as submetendo a casos concretos da realidade social. Daí a importância de seu uso no estudo de políticas de desenvolvimento de região para região dentro de um mesmo país (DULCI, 2014).

É válido situar a noção de desenvolvimento que o sociólogo propõe, qual seja, a de desenvolvimento como processo a ser investigado a partir de determinadas causas. Trata-se, em outros termos, de um projeto que pressupõe uma intencionalidade (DULCI, 2014). Assim, o autor procura investigar como se deu o desenvolvimento no estado de Minas Gerais a partir da articulação de interesses das elites da região no período pósrevolução de 1930, quando, de acordo com ele, "foi estabelecido um formato organizativo que vigora até hoje [...], e abriu um período de transição e incerteza para todos os atores, inclusive para a burguesia" (DULCI, 1999, p. 174). E, mais, foi nesse período que observamos a construção de uma ideologia: a da "mineiridade". P Para Dulci (1984), a "ideologia da mineiridade", presente na tradição política de Minas Gerais, exerceu um papel fundamental na integração de suas elites e na viabilização de seus ganhos políticos e econômicos. Esse mito foi politicamente instrumentalizado, ao longo de gerações das elites mineiras.

Em meio ao debate sobre as políticas de desenvolvimento, coloca-se como ponto importante a ser analisado o problema do desenvolvimento desigual. De acordo com Dulci, processos de industrialização tendem a se expandir do centro para a periferia, seguindo uma lógica de mercado,

\footnotetext{
${ }^{7}$ O termo "mineiridade" tem sua origem por volta de 1937, numa conferência proferida na cidade de Diamantina, por Aires da Mata Machado. Esse termo foi amplamente difundido na historiografia por Gilberto Freyre. Maria do Nascimento Arruda (1999, p. 198) explica que "a mineiridade exprime uma visão que se construiu a partir da realidade de Minas e das práticas sociais. Por fundar a figura abstrata dos mineiros, a mineiridade tem as características do mito”.
} 
tanto a nível internacional como inter-regional. Isso é patente em um leque variado de países onde há sempre uma região mais adiantada do ponto de vista industrial do que outras. Mas, para o sociólogo, às lógicas de mercado "[...] podem se sobrepor condições político-estratégicas capazes de contrabalançar as desvantagens de uma dada área, abrindo-lhe novas perspectivas de desenvolvimento" (DULCI, 1999, p. 19).

É pela relevância da dimensão política em processos de desenvolvimento que as análises de determinadas regiões ganham relevo. Como Dulci parte do pressuposto de que os rumos da industrialização nacional não são os mesmos de região para região, ele percebe que existe uma heterogeneidade nos projetos de modernização e uma consequente diversidade na maneira como as elites regionais interferem nesses projetos. Em seus próprios termos, "não se ignora obviamente a dimensão institucional, mas ela é situada no arcabouço dos interesses de classes e das estratégias das elites" (DULCI, 1999, p. 24).

Ainda hoje vemos que é premente aperfeiçoar métodos de pesquisa acerca de modelos políticos de desenvolvimento regional, numa escala intermediária entre as determinações econômicas e as intencionalidades políticas. Por essa razão, o binômio centro-periferia pode ser insuficiente para dar conta de casos que fogem ao processo de industrialização clássica do centro para as regiões periféricas. Para o caso brasileiro, Dulci parte "da proposição de que a história da industrialização brasileira envolve uma pluralidade de experiências regionais irredutíveis à via paulista” (DULCI, 1999, p. 32).

Esta visão das especificidades da industrialização nacional se choca com as visões consagradas do Pensamento Social no Brasil, como também a que Simon Schwartzman (2018) incorpora em suas análises sobre o pioneirismo de São Paulo, o qual seria modelo ideal de desenvolvimento econômico para as demais regiões do país. Por sua vez, a tese defendida por Dulci é no sentido de que o estado de Minas Gerais pode ser estudado, empiricamente, como um modelo político de desenvolvimento regional intermediário que contou com fatores de mercado conjugados com articulação política das elites locais para viabilizar seus interesses econômicos. 
$\mathrm{Na}$ visão de Dulci, uma característica fundamental do "desenvolvimentismo mineiro" foi a ideia de "recuperação econômica", notadamente a partir da Primeira República (1889-1930), momento em que os discursos das elites regionais destacavam frequentemente o cenário de atraso econômico e da necessidade de atenção e de investimentos do poder público para promover o desenvolvimento econômico regional. Apesar de interesses específicos entrarem em conflito, o ideal maior de desenvolvimento e modernização do estado estabeleceram um mínimo de consenso político para consecução de projetos e ideias desenvolvimentistas (DULCI, 1999, p. 105).

A partir de 1930, na tomada do poder político por Getúlio Vargas (CARDOSO; PEREIRA, 2020), contando com a participação ativa de jovens intelectuais de formação liberal da oligarquia mineira, como Virgílio de Melo Franco, novas propostas de superação do atraso vão se firmar no processo de modernização em Minas Gerais (NABUCO, 1962). As administrações do estado priorizaram os projetos de diversificação da economia quanto de especialização produtiva, alternando-se nas décadas de 1930 e 1940, sendo que a partir de 1951 uma "política industrial" propriamente dita começa a se desenvolver em Minas Gerais (DULCI, 1999, p. 61-62).

De acordo com a investigação de Dulci, a primeira grande iniciativa que marca a política industrial estadual é a criação do Parque Industrial em Contagem, nas proximidades da capital Belo Horizonte. Notadamente, o Parque foi criado para competir com os centros industriais de São Paulo e do Rio de Janeiro, evitando o grande afluxo de imigrantes para aquelas regiões. Destaca-se aqui a articulação do binômio "energia e transporte", slogan desenvolvimentista que vai se estruturar como política econômica do estado a partir de então, configurando um "sentido estratégico para a modernização regional" (DULCI, 1999, p. 76).

Importante destacar aqui a centralidade da atuação do estado no processo de coordenação dos projetos de desenvolvimento em Minas Gerais, mas sem desconsiderar os nexos entre estado e sociedade, notadamente o papel e as relações desempenhadas por parte das elites da região. Isso porque há determinados traços que distinguem de modo 
especial a vida econômica. Werner Sombart (2014, p. 18) afirma que, "no mundo econômico, o que importa não é tanto a invenção, mas muito mais a 'exploração' da invenção”. O que interessa a Dulci, para além das funções e resultados econômicos em si, é a ideia de "invenção", no sentido problematizado por Sombart, para a discussão de valores políticos. É por isso que ele dá importância ao discurso da conciliação política, propagado historicamente pelas elites de Minas Gerais.

Dulci vê a chamada "ideologia da mineiridade" como uma invenção no conteúdo político da experiência de desenvolvimento em Minas Gerais. Nesse estado da Federação, a capacidade das elites de se unirem em torno da formulação e implementação do projeto de desenvolvimento acabou por ser determinante politicamente, inclusive no plano nacional, pois aprenderam a lidar com suas rivalidades e concorrências. Além disso, buscaram estabelecer canais próprios de atuação que influenciaram de modo eficaz os caminhos da modernização regional. E, mais ainda, empregaram o poder de que dispunham para viabilizar seus interesses, num cenário de competição (política e econômica) entre regiões na arena nacional. Conseguiram, enfim, estabelecer metas desenvolvimentistas e estratégias de diversificação da economia. Assim se forjou o mito da "mineiridade", mito segundo o qual os mineiros são portadores da missão de promover a unidade nacional (Manifesto dos Mineiros, 1943).

Curiosamente, o sociólogo compara o projeto regional mineiro de especialização econômica, de modernização conservadora, com o modelo prussiano de desenvolvimento, por ser uma "forma paternalista de organização”. Segundo ele, “a burguesia se organiza, busca seu espaço próprio, insere-se inclusive nos escalões de governo, mas, no que toca à questão do desenvolvimento, tende a agir como setor 'tecnificado', em circuito fechado, sem interlocução real com o resto da sociedade (que ela não busca liderar, mas enquadrar)" (DULCI, 1999, p. 183).

Nessa seara interpretativa, Dulci critica os modelos de análise pautados no coronelismo/ patrimonialismo/clientelismo como marca registrada de Minas Gerais, por criarem um estereótipo de que o estado monopolizava as relações sociais. Se é verdade que a expansão do aparelho estatal cria problemas no sentido de determinados grupos pretenderem 
se apropriar de suas estruturas, não se pode negligenciar as interações no plano socioeconômico dos mais variados setores da sociedade. Assim, Dulci afirma que, no caso mineiro, várias personalidades da época exerciam papéis diversos, transitando entre ocupações públicas e privadas. Em suas palavras: "os padrões de interseção eram variados, e é essa variação que colide com a tese da separação entre a esfera política e a produtiva" (DULCI, 1999, p. 111). A marca registrada das elites mineiras, segundo Dulci, é sua polivalência, isto é, uma atuação diversificada em variados setores da sociedade: agrário, empresarial, político-partidário e técnico. Esta é uma constatação empírica que enfraquece a rigidez de análises sobre a divisão das elites (DULCI, 1999, p. 165).

A introdução de um modelo intermediário de desenvolvimento é um legado teórico-metodológico que Dulci nos deixa. Tal modelo se encaixa melhor em realidades nas quais o ímpeto de desenvolvimento do mercado está associado com a influência política de setores da sociedade, notadamente os setores dominantes ou as chamadas elites. Para analisar esses setores, Dulci utilizava um modelo interpretativo que levava em conta a trajetória de personalidades do mundo da política, do empresariado, do setor agrário e técnico, com vistas a desnudar como as conexões entre estes setores se constituíam como peça-chave para o desenvolvimento mineiro.

Para Dulci (1984), a “ideologia da mineiridade”, presente na tradição política de Minas Gerais, exerceu um papel fundamental na integração de suas elites e na viabilização de seus ganhos políticos nos âmbitos regional e nacional. O discurso da conciliação, elemento fundamental da ideologia da mineiridade, acabou por se tornar uma estratégia eficaz, politicamente, a partir da República, no esforço deliberado de superação de divergências políticas, num mesmo sistema de coalizão de interesses inter-regionais. Isso porque, "a elevada coesão interna das elites ampliou a possibilidade de levar adiante um esforço de recuperação econômica conduzido sob a égide do Estado" (DULCI, 1999, p. 238).

Por fim, vale destacar que em seu trabalho derradeiro de investigação sobre indicadores de Minas Gerais, com o apoio de colaboradores, Dulci (2016) estudou a situação social do estado e o desempenho de sua 
economia no século XXI, sob o impacto das políticas e dos programas no cenário regional, considerando sua inserção no contexto brasileiro e suas interfaces internacionais. Percebeu que, na atualidade, a ideia de mineiridade se esvai com a falta de liderança política, dando lugar ao "gerencialismo". Em tom pessimista, constata que não há mais projeto de modernização capaz de constelar diferentes grupos e classes. Do ponto de vista econômico, constata ainda que Minas Gerais obteve poucos avanços em seu processo de desenvolvimento, pois "não conseguiu diversificar e modernizar a estrutura produtiva, o que resulta em significativa dependência de commodities minerais e agropecuárias; e, não menos importante, não reduziu desigualdades sociais e regionais" (DULCI, 2016, p. 43).

Ocorre que, desde a fase de "recuperação", na primeira metade do século passado, até a atualidade, houve "perda gradual de foco da administração mineira, devido a problemas financeiros e a uma espécie de paralisia institucional no fim do século XX” (DULCI, 2016, p. 101-102). Com isso, o autor aponta a inflexão para uma linha minimalista na atuação do poder público, consorciada a um problema objetivo das últimas décadas: aumento da distância entre receitas declinantes e despesas crescentes.

Para Dulci (2016), no século XXI, a recuperação do papel do estado seria uma meta estratégica, orientada para a promoção de avanços democráticos e sociais. No entanto, Minas Gerais deixou de contar com lideranças capazes de aglutinar interesses, num mesmo projeto estratégico, cujo prestígio político possa ter capacidade para articular variadas instituições, prefeitos, parlamentares, setores empresariais e trabalhistas, como ocorreu no passado. Certamente, os últimos expoentes dessa tradição mineira - com ressonância nacional - foram Juscelino Kubitschek (1902-1976) e Tancredo Neves (1910-1985), que tiveram projeção política inicial no Partido Social Democrático (PSD), partido esse originário da máquina do Estado Novo de Getúlio Vargas e que incluía, portanto, a maior parte das elites tradicionais de Minas Gerais.

Como vimos, então, a "questão regional" se tornou crucial nas análises de Dulci, porque o envolvimento da classe política em projetos modernizantes era indispensável para manter sua posição de poder no contexto nacional e não somente a influência no estado de origem. $\mathrm{O}$ atraso 
econômico necessitava ser enfrentado - como é preciso no momento. Para enfrentar os problemas atuais, do século XXI, a mesma lógica persiste. No entanto, atualmente o foco se reorienta para as "elites modernas", os técnicos e os empresários, de "direção organizada". Os novos tipos político-institucionais implicam modalidades diferenciais de relação das atividades públicas e privadas. Daí que a agenda de pesquisa de Dulci, para o Pensamento Social no Brasil, nos possibilita debater a pertinência de surgimento ou não da "nova política", sob novas lideranças, ou mesmo se não está em curso uma estratégia deliberada de "despolitização" das ações públicas, em nome do racionalismo econômico.

\section{CONSIDERAÇÕES FINAIS}

A pesquisa social de Otavio Soares Dulci e seu estilo de interpretação sociológica contribuem, sobremaneira, para a consolidação de uma tipologia analítica no Pensamento Social do Brasil, inspirado principalmente no legado de Florestan Fernandes. No entanto, diferente de Florestan, nosso autor canaliza sua interpretação na busca de diferenças regionais e análises comparativas, procurando identificar estruturas regionais de poder e suas conexões corporativas e ideológicas com o nacional e supranacional - que ele também caracteriza como "sistema-mundo" (DULCI, 1999, p. 239).

Seguramente, o trabalho de Dulci, ao longo de sua longeva carreira acadêmica, possibilita aprofundar o estudo da diversidade regional do Brasil, para além da investigação específica sobre o caso de Minas Gerais, ressaltando o nexo entre variações econômicas e políticas no processo de modernização. Incorpora, pois, o problema das identidades regionais como recurso político, e trata tais identidades como elementos em si mesmos, com vista a compreender o conjunto e sua dinâmica.

Como vimos, Dulci (1999, p. 26) procurou priorizar as análises de estruturas regionais de poder, de modo a afirmar "a primazia de fatores políticos sobre fatores de mercado". Ao longo de sua carreira acadêmica, interessou-se pelo conteúdo de politização dos modelos de desenvolvimento. Verificou em seus estudos que o fenômeno do desenvolvimento desigual é inerentemente político e, para enfrentá-lo 
com eficácia, são necessários instrumentos políticos. Detectou que o sistema de poder se amplia, incorpora de forma seletiva novos setores e potencializa interesses. A coalizão de elites une setores tradicionais e emergentes, mantendo a centralidade da burocracia e ocupação estratégica do Estado, no que pese o discurso de defesa do liberalismo econômico.

A sociologia histórica de Dulci necessitou da trajetória de longo alcance para poder discernir acontecimentos contemporâneos. Sua sabedoria retrospectiva lhe assegura o pensar sociológico como o de um artesão intelectual, meticulosamente, encadeando acontecimentos e evidenciando contradições sociais. Contribui com o Pensamento Social no Brasil ao buscar os fundamentos da modernização pelo alto - conforme nomeia Florestan Fernandes-projetado pelas elites regionais, especialmente as de Minas Gerais, identificando na industrialização e, por conseguinte, no binômio energia-transporte, o processo de desenvolvimento até então predominante no país. No entanto, seu interesse como sociólogo e cientista político foi evidenciar contradições e desigualdades sociais.

Em uma síntese, Otavio Soares Dulci se destaca por fundamentar sua sociologia no exercício interpretativo da realidade social, cujos fatos são captados da história e das conjunturas políticas, articulando o global, o nacional e o regional. A sua contribuição intelectual é a de procurar compreender a atualidade buscando referenciais históricos em seus estudos de singularidades e experiências regionais, ancorado em tipologias que possam também ser utilizadas em estudos de contextos diferenciados. O seu legado acadêmico o coloca entre aqueles cientistas sociais brasileiros que procuram ressaltar o nexo entre determinações políticas e variações econômicas no processo de modernização, no esforço de incorporar o problema das identidades regionais como recurso político. 


\section{REFERÊNCIAS}

ARRUDA, Maria Arminda do Nascimento. Mitologia da mineiridade: o imaginário mineiro na vida política e cultural do Brasil. São Paulo: Brasiliense, 1999.

CARDOSO, Fernando Henrique. Empresário industrial e desenvolvimento econômico. São Paulo: Difusão Europeia do Livro, 1964.

CARDOSO, Fernando Henrique; FALETTO, Enzo. Dependência e desenvolvimento na América Latina: ensaios de interpretação sociológica. Rio de Janeiro: Zahar Editores, 1984.

CARDOSO, Antônio Dimas; PEREIRA, Laurindo Mekie. Intelectuais e a modernização no Brasil: os caminhos da Revolução de 1930. Montes Claros/MG: Editora Unimontes, 2020.

CHAGURI, Mariana Miggiolaro. Entre a nação e a região: produção, circulação e efeito político das ideias. Anais do XV Congresso Brasileiro de Sociologia, Curitiba-PR, de 26 a 29 de julho de 2011.

DULCI, Otávio Soares (Org.). Minas Gerais 2000-2015. São Paulo: Editora Fundação Perseu Abramo, 2016.

DULCI, Otávio Soares. Desenvolvimento Social e Contribuição das Políticas Públicas. In: Congresso em Desenvolvimento Social, IV, Conferencia. Unimontes: Montes Claros, 2014.

DULCI, Otávio Soares. Generalidade e particularidade na sociologia brasileira. Revista Sociedade e Estado. Brasília: Junho/dezembro, 2000.

DULCI, Otávio Soares. Política e Recuperação Econômica em Minas Gerais. Belo Horizonte: Ed. UFMG, 1999.

DULCI, Otávio Soares. As elites mineiras e a conciliação: a mineiridade como ideologia. Ciências Sociais Hoje, São Paulo, p. 7-31, 1984.

FERNANDES, Florestan. A revolução burguesa no Brasil: ensaio de interpretação sociológica. Rio de Janeiro: Zahar, 1976. 
FERNANDES, Florestan Economia e sociedade no Brasil: análise sociológica do subdesenvolvimento. São Paulo: Faculdade de Filosofia, Ciências e Letras (USP), Centro de Sociologia Industrial e do Trabalho, Cadeira de Sociologia, 1962.

HELAYEL, Karim. Um sociólogo na periferia do capitalismo: a sociologia histórico-comparada de Fernando Henrique Cardoso. Anais do 44 Encontro Anual da ANPOCS - GT32 - Pensamento Social no Brasil, de 01 a 11 de dezembro de 2020.

MANIFESTO DOS MINEIROS. Documento. Fundação Getúlio Vargas. Centro de Pesquisa e Documentação de História Contemporânea do Brasil. Rio de Janeiro, 1943.

MARTINS, Luciano. Industrialização, burguesia nacional e desenvolvimento. Rio de Janeiro: Saga, 1968.

NABUCO, Carolina. A vida de Virgílio de Melo Franco. Rio de Janeiro: Livraria José Olympio Editora, 1962.

PREBISCH. Raúl. O desenvolvimento econômico da América Latina e alguns de seus problemas principais. Revista Brasileira de Economia, v. 3, n. 3, 1949 .

RAMOS, Alberto Guerreiro. A redução sociológica. Rio de Janeiro: Editora UFRJ, 1996.

SCHWARTZMAN, Simon. Bases do Autoritarismo Brasileiro. Campinas/SP: Editora Unicamp, 2018.

SOMBART, Werner. Os judeus e a vida econômica. São Paulo: Editora Unesp, 2014.

TROTSKI, Leon. História da Revolução Russa. Rio de Janeiro: Saga, 1967.

VEBLEN, Thorstein. A Alemanha Imperial e a Revolução Industrial. In: James - Dewey - Veblen. São Paulo: Abril, 1974 (Coleção Os Pensadores, v. XI). 
VIANNA, Oliveira. Evolução do Povo Brasileiro. São Paulo: Nacional, 1938.

VILLA BÔAS, Glaucia. 80 anos de Ciências Sociais na UFRJ: relembrando o pioneirismo dos projetos Grupos Econômicos (1962) e Trabalhadores Cariocas (1987). Revista Sociologia \& Antropologia. Rio de Janeiro, v. 09, p. 297-312, 2019.

Texto recebido em 29/08/2020 e aprovado em 22/02/2021 